\title{
Anger of Women Incest Survivors ${ }^{1}$
}

\author{
Amy L. Newman ${ }^{2}$ \\ Davis, California \\ Christopher Peterson ${ }^{3}$ \\ University of Michigan
}

Adult women survivors of incest $(\mathrm{n}=68$ ) were compared to other women $(\mathrm{n}$ =93) with respect to several questionnaire measures of manifest anger. The vast majority of the research participants were white, middle class, heterosexual, and Michigan residents. Incest survivors were angrier than other women, both in general and at their parents. Anger toward mother and anger toward father were comparable. Few incest survivors blamed either parent for the incest, except in those speciflc cases where the parent was a perpetrator. Not surprisingly, incest survivors were particularly angry at parent perpetrators when they were held responsible for the abuse. Incest occurred in families where other traumas were present, and the extent of these other traumas was also associated with increased anger at parents. Women who identified with feminism and who had participated in therapy were angrier at their parents than were other women. Therapy implications of these results were discussed.

Recent decades have seen hundreds of articles on incest appear in professional journals. Their usual goal is to describe the families in which incest occurs, recommend interventions with the victim and family, and speculate

\footnotetext{
${ }^{1}$ This paper is based on a doctoral dissertation submitted to the University of Michigan by the first author, under the supervision of the second author. The help and encouragement of committee members Margaret Buttenheim, Kathleen Faller, and Sheryl Olson are gratefully acknowledged. Howard Gottlieb, Judith Ballou, Donna Silbert, and Robert Daniels also contributed substantially to this research.

Financial support was provided by the Society for the Psychological Study of Social Issues, the Horace D. Rackham School of Graduate Studies, and the Department of Psychology at the University of Michigan.

${ }^{2}$ To whom reprint requests should be addressed at 1260 Lake Boulevard, Davis, CA 95616.

${ }^{3}$ To whom correspondence should be addressed at Department of Psychology, University of Michigan, 525 East University, Ann Arbor, Michigan 48109-1109.
} 
about the motives of the perpetrator and the often-criticized mother of the victim. A smaller literature addresses the long-term aftermath of familial sexual abuse for survivors. Research in this area has explored the consequences for victims: depression, anxiety, low self-esteem, feelings of isolation and stigma, revictimization, substance abuse, sexual difficulties, and so on (e.g., Browne \& Finkelhor, 1986).

Relatively neglected in empirical research to date is the experience of anger by adult women survivors of incest. This neglect occurs despite frequent theoretical speculation that survivors are angry, in particular at their mothers because of unconscious dynamics that lead them to blame their mothers for "allowing" the abuse to occur and/or continue (e.g., Herman, 1981; Rosenthal \& Doherty, 1985). However, it is not clear whether this putative anger at their mothers distinguishes incest survivors from many other adult women, who are also thought to be angry at their mothers (e.g., Herman \& Lewis, 1986; Lerner, 1985; Schaef, 1985).

The present research explored some of these issues by comparing female incest survivors to other women with respect to several aspects of manifest anger, specifically its experience and expression. Most empirical investigations of anger of incest survivors have been case studies (e.g., Brown, 1993; Duenas, 1986; Price, 1985) and/or have lacked comparison groups (e.g., DelPo \& Koontz, 1991; Goodwin, Cheeves, \& Connell, 1990; Sharma \& Cheatham, 1986), so our research goes beyond typical attempts to address this topic.

Also of interest here was whether specific characteristics of incest and its aftermath-such as the identity of the perpetrator, the extent of the abuse, the person held responsible, and disclosure of the incest-were associated with the degree of anger among survivors. We also asked our research participants about other traumas within the family. Finally, we investigated the relationships to anger of an identification with feminism and the experience of therapy and self-help groups.

\section{METHOD}

\section{Subjects and Procedure}

Participants in this study were 161 women between the ages of 20 and 90 inclusive, the vast majority of whom were white, middle class, heterosexual, and Michigan residents. Their mean age was 37 , and their mean level of education was between an associate's degree and a bachelor's degree. About one third of the subjects were single, one third married, and the remaining third separated, divorced, or living with a partner. Partici- 
pants included 68 self-identified incest survivors and 93 women who did not report that they had been victims of incest. Seventy-nine percent of survivors and $54 \%$ of controls had been in therapy.

The two groups were relatively well-matched for age (36 versus 38 years of age, for survivors and controls, respectively), ethnicity (91\% versus $89 \%$ white), socioeconomic status ( $\$ 25000$ versus $\$ 31000$ yearly income), partnered status (38\% versus $33 \%$ single; $31 \%$ versus $44 \%$ married; $31 \%$ versus $23 \%$ other), and sexual orientation ( $78 \%$ versus $88 \%$ heterosexual).

The incest survivors were recruited in several ways. Fourteen women responded to an ad placed in a local newsletter written by and for women who were sexually abused as children. Twelve women responded to flyers distributed at a public lecture in Ann Arbor on incest. The remaining 42 survivors responded to flyers distributed to self-help groups such as Survivors of Incest Anonymous in the Ann Arbor and Detroit areas, to a flyer posted at a shelter for battered women, and to flyers distributed to therapists. Seven women contacted to be part of the comparison group were reassigned to the incest group when they reported that they were incest survivors.

Women in the comparison group were contacted through ads and flyers inviting participation in a study of women's relationships with their female friends and with their mothers. Ads were placed in the University of Michigan staff newspaper and in a local food co-op newsletter. Flyers were posted in popular restaurants in Ann Arbor and Royal Oak. Questionnaires were also distributed face-to-face in University of Michigan offices, bookstores catering to women, and local women's organizations such as the Ann Arbor Women's City Club.

Individuals expressing interest in participating were given information by the researchers either in person or by phone about the requirements of the study. Only three individuals declined participation. Each subject was given a questionnaire to complete and a stamped and addressed envelope in which to return it to the researchers. Of the 180 distributed questionnaires, 161 were returned, a response rate of $89 \%$.

\section{Questionnaire}

The same questionnaire was given to all women in the study; women who were not incest survivors were instructed to skip over those sections specifically pertaining to incest. The questionnaire consisted of a number of sections (see Newman \& Peterson, 1995). Those relevant for the present purposes, in the order in which they appeared in the questionnaire, included: 
Basic Information. Here the respondent provided information about her age, income, education, occupation, ethnicity, sexual orientation, and partnered status.

Feminism. This was a 22-item questionnaire developed for the present research to assess a respondent's affinity for feminist views. Such items as "this society supports the oppression of women" and "I consider myself a feminist" were responded to on a 5-point scale of agreement. Reliability estimated by Cronbach's (1951) coefficient alpha was .90 .

Anger. Spielberger's (1991) State-Trait Anger Expression Scale (STAXI) was administered. This scale yields separate scores for:

- state anger (the intensity of anger as an emotional state) (10 items)

- trait anger (the habitual experience of feelings of anger) (10 items)

- angry temperament (the tendency to experience anger) (4 items)

- angry reaction (the tendency to respond with anger) (4 items)

- anger-in (the tendency to hold anger in) (8 items)

- anger-out (the tendency to express anger openly) (8 items)

- anger control (the tendency to control anger expression) (8 items)

The STAXI was used as Spielberger designed, except that the state anger subscale was administered three different times, with instructions to the subject to respond by thinking back to her childhood and bring to mind the following people: (a) her father; (b) her mother; and (c) the perpetrator of incest if he or she were other than or besides the parents.

Reliabilities for these various measures, estimated by coefficient alpha, were .97 for state anger concerning father, .97 for state anger concerning mother, .93 for state anger concerning a nonparent perpetrator, .79 for trait anger, .86 for angry temperament, .69 for angry reaction, .82 for anger-in, .53 for anger-out, and .81 for anger control. These reliabilities were satisfactory, except for the anger-out measure.

Traumatic Events. Subjects were asked about the occurrence of a variety of traumatic events during childhood: separations, losses, emotional abuse, neglect, substance abuse by caretakers, exposure to violence, physical abuse, torture, isolation, sexual abuse by non-relatives, and the like. Respondents indicated the extent to which such events occurred on 4-point scales (from never to always).

Incest. This section asked for information about incest, which was described for subjects as:

Childhood experiences ... of sexual contact with a relative. This includes open mouth kissing; intentional touching of buttocks, thigh, or leg in a sexual or seductive manner; breast contact, clothed or unclothed; body contact such as a hug that seems sexual; manual genital contact, clothed or unclothed; oral-genital contact; attempted or completed intercourse. For the purpose of this study, there must have been physical sexual contact by a relative. Relatives include immediate as well as distant 
family, such as a distant cousin. Family may be biological, by marriage (e.g., brother-in-law), foster, adoptive, or step. Mother's boyfriend who lived with the family as a step-father is considered family for this study. A close friend of the family is not.

Subjects were asked to indicate whether incest had occurred, their age when incest began, the age and identity of the abuser(s), the use of force, and the duration of abuse. Subjects were also asked to characterize the incest as sadistic, bizarre, or pleasurable, as applicable. Furthermore, each respondent indicated whether she had disclosed the incest to her mother, when she did so, and the response of her mother (positive or negative). All lncest survivors were asked to indicate the person(s) they held responsible for the incest at the time it occurred as well as at the present time.

Therapy and Self-Help. Finally, subjects were asked if they had been involved in therapy or self-help groups at any point in their lives.

\section{RESULTS}

\section{Characteristics of Incest}

The most commonly reported perpretrator of incest was the biological father, who sexually abused $47 \%$ of the incest survivors in this sample. Brothers abused $31 \%$ of the survivors, mothers $18 \%$, and step-fathers $9 \%$. Included in the preceding figures were the $9 \%$ of survivors who were victimized by both parents. Also reported as abusers by one or two subjects were uncles, cousins, grandparents, or other relatives.

On average, incest began when the individual was five years of age and lasted for eight years. Penetration of some part of her body (other than mouth-to-mouth kissing) occurred in $72 \%$ of cases. Physical force was used with $47 \%$ of the survivors during sexual abuse, and another $43 \%$ reported being threatened. Thirty-five percent of the survivors described the abuse as sadistic, meaning that the abusers took apparent pleasure in causing them pain, and $19 \%$ considered the abuse especially bizarre, such as being forced to have sex with an animal. Sixty-two percent of the survivors reported that-at least sometimes-they had experienced physical pleasure during the abuse.

\section{Anger: Between-Group Comparisons}

Table I compares survivors and controls on their responses to the various anger measures. As can be seen, survivors scored higher on many of the measures, both for anger in general and anger specifically at their parents. 
Table I. Means and Standard Deviations of Anger Measures

\begin{tabular}{lccc}
\hline \multicolumn{1}{c}{ Measure (See Text) } & Survivors & Controls & $t$ \\
\hline Anger at mother & $24.25(9.87)$ & $13.21(4.09)$ & $8.37^{b}$ \\
& & & \\
Anger at father & $23.84(10.77)$ & $12.60(5.48)$ & $8.34^{b}$ \\
& & & \\
Anger at nonparent abuser & $24.07(8.91)$ & & \\
& & & \\
Trait anger & $20.82(5.14)$ & $18.82(4.09)$ & $2.75^{a}$ \\
$\quad$ Angry temperament & $6.84(2.51)$ & $6.23(2.20)$ & 1.64 \\
Angry response & $10.40(2.75)$ & $9.64(2.32)$ & 1.89 \\
& & & \\
Anger expression & $25.46(7.78)$ & $22.27(7.72)$ & $4.75^{b}$ \\
Anger-in & $18.85(4.79)$ & $15.44(4.11)$ & $4.85^{b}$ \\
Anger-out & $14.38(2.52)$ & $15.05(3.00)$ & -1.50 \\
Anger control & $23.78(4.83)$ & $24.22(4.24)$ & -0.61 \\
\hline$a p<.01$. & & & \\
$b p<.001$. & & & \\
& & &
\end{tabular}

Anger: Within-Group Comparisons

No statistically significant difference was found between the extent of anger at mother versus father, for either the survivor group $(t=.64$, ns) or the comparison group $(t=1.09, \mathrm{~ns})$. Indeed, anger at mother and anger at father correlated substantially within both groups $(\mathrm{r}=.54, .62$; for surviviors and controls, respectively; each $\mathrm{p}<.001$ ). Among the survivors, anger at nonparent perpetrators was comparable to that at either parent. Among the survivors of incest, there was no statistically significant difference in the extent of anger at mother or father as a function of the identity of the perpetrator. Anger at both mother and father was increased to the degree that incest began at an early age $(r=.40, .40$; for anger at mother and anger at father, respectively; each $\mathrm{p}<.001)$, lasted longer $(\mathrm{r}=.34$, .39 ; each $\mathrm{p}<.005)$, involved penetration $(\mathrm{r}=.34, .28$; each $\mathrm{p}<.05)$, and lnvolved force $(\mathrm{r}=.35, .26$; each $\mathrm{p}<.05)$.

\section{Responsibility}

Table II reports the person(s) the survivors held most responsible for incest, when they were children and presently as adults. As children, 54\% of the survivors blamed themselves, and $21 \%$ blamed a nonparent abuser. Even when parents were abusers, survivors as children were not likely to blame them. As adults, only $6 \%$ blamed themselves, and there was an increased likelihood to hold actual abusers responsible. The anger measures were not correlated with who was held responsible for the incest, except 
Table II. Person Held Most Responsible for Incest ${ }^{a}$

\begin{tabular}{lcc}
\hline Person blamed & $\begin{array}{c}\text { By survivors } \\
\text { as child }\end{array}$ & $\begin{array}{c}\text { By survivor } \\
\text { as adult }\end{array}$ \\
\hline Mother (not an abuser) & 5.9 & 2.9 \\
Mother (abuser) & 4.4 & 22.1 \\
Father (not an abuser) & 5.9 & 2.9 \\
Father (abuser) & 8.8 & 38.2 \\
Nonparent abuser & 20.6 & 38.2 \\
Self & 54.4 & 5.9 \\
\hline
\end{tabular}

${ }^{a}$ Figures are percentages of survivors who blamed (i.e., held most responsible) each category of person, both as a child and as an adult. Percentages exceed 100 because some survivors held more than one person primarily responsible. $<.01$.

in cases where the mother or father was the actual perpetrator; so, anger at mother was correlated with holding her responsible when she was an abuser $(r=.38, p<.001)$ but not otherwise, and anger at father was correlated with holding him responsible when he was an abuser $(\mathrm{r}=.25, \mathrm{p}$ $<.05$ ) but not otherwise.

\section{Disclosure}

Among the incest survivors, $33 \%$ as children disclosed the abuse to their mothers, and $50 \%$ as adults discussed the abuse with their mothers. No relationship was found between disclosure per se and measures of anger. No correlation was evident between a positive response on the part of the mother to disclosure and any of the anger measures. When the response to disclosure was negative, several of the general anger measures were increased (angry temperament: $\mathrm{r}=.36, \mathrm{p}<.001$; anger-out: $\mathrm{r}=.27$, $\mathrm{p}<.05$; and anger control: $\mathrm{r}=-.27, \mathrm{p}<.05$ ): However, anger specifically at the mother was not found to be associated with her reaction to disclosure, even when it was negative $(r=.09, \mathrm{~ns})$.

\section{Childhood Trauma}

Other than incest, the survivor group experienced a greater number of traumas and abuse of all kinds than did the comparison group. Ninety percent of the survivor group versus $71 \%$ of the comparison group reported 
at least one type of abuse other than incest (chi square $=21.57, \mathrm{p}<.01$ ). The experience reported most frequently by the comparison group was "heated arguments in the family" (57\%), whereas emotional abuse was reported by $85 \%$ of the survivors, physical abuse by $74 \%$, and neglect by $63 \%$. The frequency of childhood traumas was correlated with anger at mother $(\mathrm{r}=.27, \mathrm{p}<.05)$ and at father $(\mathrm{r}=.28, \mathrm{p}<.025)$, particularly among the incest survivors.

\section{Feminism}

Survivors were more likely to agree with feminist ideas than were women in the comparison qroup (scale means: 107.6 versus $100.1, t=3.24$, $\mathrm{p}<.001$ ). Among all subjects, agreement with feminist ideas was not associated with any of the anger measures except anger at mother $(\mathrm{r}=.38$, $\mathrm{p}<.001)$ and anger at father $(\mathrm{r}=.30, \mathrm{p}<.025)$; when calculated separately, the magnitudes of these correlations were comparable in both groups. When agreement with feminist ideas was statistically controlled, the already-described differences in anger between the two groups remained significant.

\section{Therapy and Self-Help}

Among all subjects, agreement with feminist ideas was correlated with the experience of therapy $(\mathrm{r}=.33, \mathrm{p}<.001)$ and self-help groups $(\mathrm{r}=$ $.21, \mathrm{p}<.05$ ); when calculated separately, the magnitudes of these correlations were not significantly different between groups. Among all subjects, experience of therapy was correlated with anger at mother $(\mathrm{r}=.42, \mathrm{p}<$ $.001)$ and anger at father $(r=.38, p<.001)$; when calculated separately, the magnitudes of these correlations were not significantly different between groups. Among the survivors, those in therapy were more likely to have been abused at an earlier age $(r=-.45, p<.001)$ and for a longer period of time $(r=.30, p<.025)$. When experience with therapy was statistically controlled, the already-described differences in anger between the two groups remained significant. Results involving experience of selfhelp groups were similar though less robust.

\section{DISCUSSION}

This study explored several aspects of anger experienced by adult incest survivors. Here are the major findings. First, incest survivors were an- 
grier than other women, both in general and at their parents. Overall, there was no difference between the anger at mothers versus fathers, which is at odds with the speculation by some writers that the brunt of negative feelings engendered by incest is directed at the mother (e.g., Herman, 1981; Jacobs, 1990; Winer, 1989). Perhaps clinical theorists were so surprised that women abused by their fathers were angry at their mothers that they missed the obvious: survivors were just as angry at their fathers. Indeed, women abused by one parent-whether mother or father-were equally angry at the other parent.

Second, a positive response by a survivor's mother to disclosure did not reduce anger, whereas a negative response tended to increase it. These results suggest that the negative impact of incest is more readily exacerbated than it is ameliorated.

Third, very few survivors blamed their mothers for the incest, either as children or currently as adults. And only when the mother was actually an abuser did the tendency to blame her correlate with anger toward her. The same pattern held for fathers.

Fourth, more than half of the survivors (54\%) blamed themselves for the incest as children, yet only $6 \%$ did so as adults. This is an important finding, implying that most incest survivors as adults come to at least an intellectual understanding that they were victims. This realization can perhaps serve as a point of departure in therapy.

Fifth, incest tended to occur in families where other forms of trauma had taken place. Only $10 \%$ of the survivors in the present sample reported no other chlldhood trauma than incest. What this means is that disentangling the specific effects of incest from associated traumas can be difficult if not impossible. Anger at parents was a direct function of the extent of these other types of abuse. A great deal of theory and research into trauma is trauma specific, but the present results imply that a broader view is needed that recognizes the multiplicity of trauma. Further work might go beyond our approach of simply asking about the occurrence of various traumatic events to ask how they were interpreted and resolved.

Sixth, anger at mothers (and fathers) was associated with one's tendency to agree with feminist ideas and with whether one had been in therapy. Identifying cause and effect here is of course impossible, but if nothing else, these results suggest that feminism and therapy-at least as typically experienced by our subjects-did not remove negative feelings toward one's mother, even in cases where she was not held responsible for the occurrence of incest. Perhaps this finding is unsurprising; therapy and identification with feminism may, at least in the short term, heighten an incest survivor's awareness and expression of anger. Indeed, it is legitimate and perhaps beneficial for incest survivors to be angry about specific individuals 
and occurrences, but highly generalized anger might well create problems elsewhere in their adult lives.

The present study has several limitations. The most obvious problem was the recruitment of participants. Subjects self-selected themselves into the study, and thus their representativeness is unknown. Control subjects were aware that the study was concerned, at least in part, with incest, and their responses might have been affected by this knowledge. Both survivor and comparison groups were better educated than the average American woman, and therapy was a great deal more common among both groups than in the general population. The participants were overwhelmingly white and middle class, and professional women were over-represented. Despite the possible limits on the generality of our findings, the present study represents a methodological improvement over many previous investigations of anger among incest survivors in that it included a relatively large number of survivors and used a comparison group.

Women in the two groups we studied were compared to each other on number of measures, which raises the possibility that the obtained results capitalized on chance. However, the overall patter of statistically significant findings was highly consistent, and individual comparisons often achieved significance at the .001 level or beyond (see again Table 1). All subjects were studied at a single point in life, and their retrospective reports were taken at face value. A preferable approach would have been to study incest survivors and their anger over time, supplementing self-reports with measures completed by other people.

We asked a number of questions about anger, because theoretical speculation so frequently points to anger as common among incest survivors. However, anger is just one of many emotions that might be experienced by incest survivors. Although they experience anger more intensely than do other individuals, the same might be true for other emotions as well. Further research is needed.

These shortcomings aside, the present research makes a contribution by systematically investigating the anger of adult survivors of incest. Survivors differed from controls, often in ways at odds with clinical theory and lore. The present results seem more consistent with common sense than with occasional speculations based on the operation of unconscious displacement of anger (cf. Solin, 1986). We presume that incest survivors are generally angry at their parents because they experienced a traumatic childhood. The more severe the abuse, the angrier the survivors are; the more extensive other traumas, the angrier they are.

The present results have several implications for therapy with incest survivors. Therapists should expect survivors of incest to be angry, not just at their parents but in general. They should not be surprised if therapy 
does not in the short term readily reduce this anger. While incest survivors may be encouraged to express their feelings openly in therapy, they should probably not be misguided into believing that they should do so freely in all relationships, as this can take a toll on friendships (see Newman \& Peterson, 1995). Most useful, we believe, would be guidance about identifying appropriate anger and its expression.

At the same time that the appropriate anger of incest survivors is recognized and respected, therapists might also want to undertake assertiveness training to help survivors reduce their inappropriate anger and better negotiate conflict. Such treatment might help incest survivors set limits on distressing interactions with their parents and others, and cultivate rewarding relationships.

\section{REFERENCES}

Brown, G. N. (1993). Borderline states: Incest and adolescence. Journal of Analytical Psychology, 38, 23-35.

Browne, A.. \& Finkelhor, D. (1986). Impact of child sexual abuse: A review of research. Psychological Bulletin, 99, 66-77.

Cronbach, L. J. (1951). Coefficient alpha and the internal structure of tests. Psychometrika, $16,297-334$.

DelPo, E. G., \& Koontz, M. A. (1991). Group therapy with mothers of incest victims: II. Therapeutic strategies, recurrent themes, interventions, and outcomes. Archives of Psychiatric Nursing, 5, 70-75.

Duenas, M. T. (1986). Impact of long term sexual abuse. Clinical Gerontologist, 4, 47-50.

Goodwin, J. M., Cheeves, K., \& Connell, V. (1990). Borderline and other severe symptoms in adult survivors of incestusous abuse. Psychiatric Annals, 20, 22-32.

Herman, J. L. (1981). Father-daughter incest. Cambridge, MA: Harvard University Press.

Herman, J. L., \& Lewis, H. B. (1986). Anger in the mother-daughter relationship. In T. Bernay \& D. W. Cantor (Eds.), The psychology of today's woman: New Psychoanalytic visions. Hillsdale, NJ: Analytic Press.

Jacobs, J. L. (1990). Reassessing mother blame in insest. Signs: Journal of Women in Culture and Society, 15, 500-514.

Lerner, H. G. (1985). The dance of anger. New York: Harper \& Row.

Newman, A. L., \& Peterson, C. (1995). Relationships of women incest survivors with mothers and female friends. Unpublished manuscript, University of Michigan.

Price, G. M. (1985). Fathers provoke not your children: A study of rage in a sexually abused girl. Journal of Psychology and Christianity, 4, 71-75.

Rosenthal, P. A., \& Doherty, M. B. (1985). Psychodynamics of delinquent girls' rage and violence directed toward mother. Adolescent Psychiatry, 12, 281-289.

Schaef, A. W. (1985). Women's reality: An emerging female system in a white male society. New York: Harper \& Row.

Sharma, A., \& Cheatham, H. E. (1986). A women's center support group for sexual assault victims. Journal of Counseling and Development, 64, 525-527.

Solin, C. A. (1986). Displacement of affect in families following incest disclosure. American Journal of Orthopsychiatry, 56, 570-576.

Spielberger, C. D. (1991). State-trait anger expression inventory. revised research edition: Professional manual. Odessa, FL: Psychological Assessment Resources. 
Winer, R. (1989). The role of transitional experience in development in healthy and incestuous families. In J. S. Scharff (Ed.), Foundations of object relations family therapy. Northvale, NJ: Jason Aronson. 